\title{
Use of nucleotide analogs by class I and class II CCA-adding enzymes (tRNA nucleotidyltransferase): Deciphering the basis for nucleotide selection
}

\author{
HYUNDAE D. CHO, ${ }^{1}$ ADEGBOYEGA K. OYELERE, ${ }^{2}$ SCOTT A. STROBEL, ${ }^{2}$ and ALAN M. WEINER ${ }^{1}$ \\ ${ }^{1}$ Department of Biochemistry, School of Medicine, University of Washington, Seattle, Washington 98195-7350, USA \\ ${ }^{2}$ Department of Molecular Biophysics and Biochemistry, Yale University, New Haven, Connecticut 06520-8114, USA
}

\begin{abstract}
We explored the specificity and nature of the nucleotide-binding pocket of the CCA-adding enzyme (tRNA nucleotidyltransferase) by using CTP and ATP analogs as substrates for a panel of class I and class II enzymes. Overall, class I and class II enzymes displayed remarkably similar substrate requirements, implying that the mechanism of CCA addition is conserved between enzyme classes despite the absence of obvious sequence homology outside the active site signature sequence. CTP substrates are more tolerant of base modifications than ATP substrates, but sugar modifications prevent incorporation of both CTP and ATP analogs by class I and class II enzymes. Use of CTP analogs (zebularine, pseudoisocytidine, 6-azacytidine, but not 6-azauridine) suggests that base modifications generally do not interfere with recognition or incorporation of CTP analogs by either class I or class II enzymes, and that UTP is excluded because N-3 is a positive determinant and/or O-4 is an antideterminant. Use of ATP analogs $\left(N^{6}\right.$-methyladenosine, diaminopurine, purine, 2-aminopurine, and 7-deaza-adenosine, but not guanosine, deoxyadenosine, 2'-O-methyladenosine, 2'-deoxy-2'-fluoroadenosine, or inosine) suggests that base modifications generally do not interfere with recognition or incorporation of ATP analogs by either class I or class II enzymes, and that GTP is excluded because N-1 is a positive determinant and/or the 2-amino and 6-keto groups are antideterminants. We also found that the $3^{\prime}$-terminal sequence of the growing tRNA substrate can affect the efficiency or specificity of subsequent nucleotide addition. Our data set should allow rigorous evaluation of structural hypotheses for nucleotide selection based on existing and future crystal structures.
\end{abstract}

Keywords: tRNA; nucleotidyltransferase; nucleotide analogs; chemogenetics; collaborative templating; scrunching

\section{INTRODUCTION}

The CCA-adding enzyme [ATP (CTP): tRNA nucleotidyltransferase] uses CTP and ATP as substrates to build and repair the 3' end of tRNA (Sprinzl and Cramer 1979; Deutscher 1982). CCA-adding activity is present in all three kingdoms (Yue et al. 1996; Tomita and Weiner 2001), and is essential for tRNA biosynthesis in organisms that do not encode the $3^{\prime}$-terminal CCA, including eukaryotes, many archaea, and some eubacteria (Zhu and Deutscher 1987). In organisms that encode CCA, such as the gram negative eubacterium Escherichia coli, the CCA-adding enzyme repairs the $3^{\prime}$-terminal CCA sequence but is not essential

Reprint requests to: Alan M. Weiner, Department of Biochemistry, School of Medicine, University of Washington, Seattle, WA 98195-7350, USA; e-mail: amweiner@u.washington.edu.

Article and publication are at http://www.rnajournal.org/cgi/doi/ 10.1261/rna.2110903.
(Zhu and Deutscher 1987; Li and Deutscher 1994; Li et al. 1998). CCA-adding enzymes belong to the nucleotidyltransferase superfamily, which can be divided into two distinct classes (Yue et al. 1996): Class I enzymes include the archaeal CCA-adding enzymes, eukaryotic poly(A) polymerases, DNA polymerase $\beta$, terminal deoxynucleotidyltransferase (TdT), kanamycin nucleotidyltransferase, and streptomycin adenyltransferase. Class II enzymes include eubacterial and eukaryotic CCA-adding enzymes, eubacterial CC- and A-adding enzymes (Tomita and Weiner 2001), and eubacterial poly(A) polymerases.

CCA-adding enzymes recognize tRNA or tRNA-like structures, and catalyze CCA addition in a primer-dependent, template-independent manner (Shi et al. 1998b; Cho et al. 2002). Three different kinds of enzymes are known to add nucleotides in a primer-dependent but template-independent fashion: poly(A) polymerases, terminal deoxynucleotidyltransferase, and the CCA-adding enzymes (Yue 
et al. 1996; Martin et al. 1999, 2000) as well as the closely related CC- and A-adding enzymes (Tomita and Weiner 2001). In contrast to CCA-, CC-, and A-adding enzymes that add a defined sequence of defined length, poly(A) polymerase and terminal deoxynucleotidyltransferase synthesize products of heterogeneous length and require only that the primer be of the correct chemical composition-RNA for poly(A) polymerase and DNA for terminal deoxynucleotidyltransferase (Martin et al. 1999, 2000).

The CCA-adding enzyme has a single active site containing a catalytic DXD motif (Yue et al. 1998), and the tRNA substrate appears to remain fixed on the enzyme surface throughout CCA addition (Shi et al. 1998a). To explain how CCA addition occurs without tRNA translocation, we proposed a "collaborative templating" model in which the growing 3' terminus of the tRNA progressively refolds, allowing the solitary active site to reuse a single CTP-binding site (Shi et al. 1998a; Yue et al. 1998). The ATP-binding site would then be created collaboratively by the refolded CC terminus and the enzyme, and nucleotide addition would cease when the nucleotide-binding pocket is full (Shi et al. 1998a; Yue et al. 1998).

The collaborative templating model predicts that the specificity of CCA addition depends on unique, precise packing of the nucleotide-binding pocket. To test this prediction and to explore the rules for packing the nucleotidebinding pocket, we assayed the ability of class I and II enzymes to use CTP and ATP analogs that have unnatural substituents, or lack natural substituents on the purine, pyrimidine, and ribose rings. Similar nucleotide analogs have been used previously for understanding DNA or RNA polymerase activity (Armstrong et al. 1976; Eckstein et al. 1982; Romaniuk and Eckstein 1982; Guo et al. 1998) as well as RNA structure and function (Eckstein and Gish 1989; Gaur and Krupp 1993; Abramovitz et al. 1996; Hardt et al. 1996; Ryder and Strobel 1999). Indeed, introduction of nucleotide analogs into 3 '-terminal tRNA substrates by the CCA-adding enzyme itself has helped to understand the mechanism of CCA addition (Sprinzl et al. 1972, 1973a, 1973b, 1977; Cramer et al. 1975; Sprinzl and Cramer 1979). However, these pioneering studies of the CCA-adding enzyme often used very high concentrations of nucleotide analogs (5 mM instead of 30 to $200 \mu \mathrm{M}$ ) and nearly stoichiometric levels of enzyme (1:1 instead of 1:100; Sprinzl et al. 1973b, 1977; Zachau and Hertz 1974) thus potentially generating aberrant products caused by tRNA binding, rebinding, or slipping out of register on the enzyme.

Using a panel of nucleotide analogs and both class I and class II CCA-adding enzymes, we explored the nature of the nucleotide-binding pocket, and the specificity of nucleotide addition. Our data argue against a collaborative templating model, but we find that the two classes of CCA-adding enzymes make very similar use of CTP and ATP analogs. This suggests that the class I enzymes of archaea and the class II enzymes of eubacteria and eukaryotes-although lacking detectable homology outside the immediate vicinity of the nucleotidyltransferase motif-use similar mechanisms to template CCA addition. Our data are also consistent with the recently determined crystal structure for the class II CCA-adding enzyme of Bacillus stearothermophilus complexed with CTP or ATP (Li et al. 2002), and should allow rigorous evaluation of hypotheses for nucleotide selection when a class I crystal structure becomes available.

\section{RESULTS}

\section{Stereochemistry of CCA addition}

To take advantage of the large collection of nucleotide analogs originally synthesized as phosphorothioate triphosphates for nucleotide analog interference mapping (Strobel and Shetty 1997; Ryder and Strobel 1999), we first determined whether representative CCA-adding enzymes incorporate the $\mathrm{R}_{\mathrm{p}}$ or $\mathrm{S}_{\mathrm{P}}$ diastereomer. Using the class I enzyme from the archaeon Sulfolobus shibatae, and the class II enzyme from the gram positive eubacterium B. stearothermophilus, we assayed addition of the $S_{P}$ or $R_{P}$ diastereomers of CTP and ATP to uniformly labeled tRNA substrates lacking CA or A (tRNA-DC and tRNA-DCC where D is the discriminator base). We found that both class I and II enzymes use the $\mathrm{S}_{\mathrm{P}}$ diastereomer exclusively, like other DNA (Eckstein 1985; Eckstein and Thomson 1995) and RNA polymerases (Knowles 1980; Ryder and Strobel 1999); moreover, addition of the $S_{P}$ diastereomers is complete under standard assay conditions, suggesting that the $S_{P}$ $\alpha$-phosphorothiorates do not significantly inhibit the reaction (Fig. 1). We therefore used the $S_{P}$ diastereomer of CTP

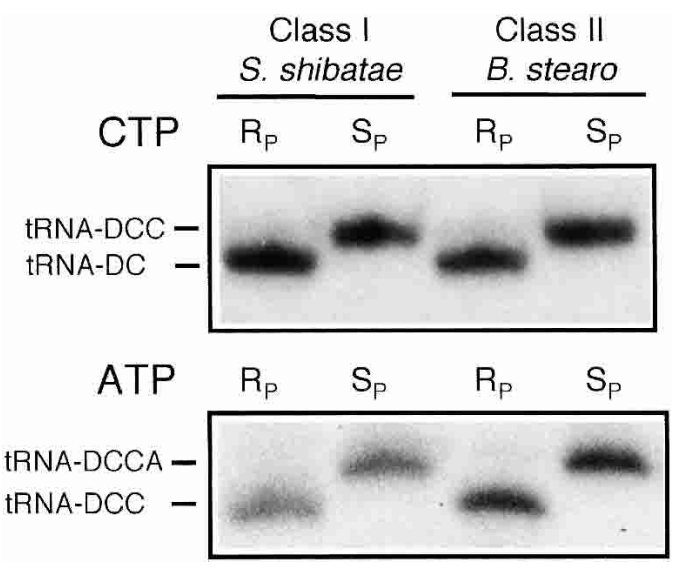

FIGURE 1. Stereochemistry of CCA addition. Addition of the $R_{P}$ and $S_{\mathrm{P}}$ isomers of CTP or ATP to tRNA lacking CA or A was assayed under standard conditions using $100 \mu \mathrm{M}$ CTP $\left(\mathrm{R}_{\mathrm{P}}\right.$ and $\left.\mathrm{S}_{\mathrm{P}}\right)$ or $200 \mu \mathrm{M}$ ATP $\left(R_{P}\right.$ and $\left.S_{P}\right)$. Although modest addition was observed when the concentration of the $\mathrm{R}_{\mathrm{P}}$ isomer of ATP was increased to $600 \mu \mathrm{M}$ (data not shown), this presumably reflects incorporation of $S_{P}$ isomer slightly contaminating the $\mathrm{R}_{\mathrm{P}}$ preparation; mixing experiments suggested that a $10 \%$ contamination of $R_{P}$ with $S_{P}$ could account for the data. 
and ATP analogs throughout this work, except for commercially available 8 -azido-ATP and 2-azido-ATP.

Under our standard assay conditions, enzyme is present at catalytic levels (enzyme to tRNA substrate ratio, 1:100), nucleotide concentrations are within the physiological range $(200 \mu \mathrm{M}$ for CTP analogs), and tRNA precursors are present at roughly physiological concentrations $(2 \mu \mathrm{M}) 100$ to 1000-fold below those of mature tRNA (Yue et al. 1996). To survey and compare many different analogs, we initially kept nucleotide concentrations constant for almost all analogs, and incubated all reactions three times longer than required for completion with the natural nucleotide substrates CTP and ATP (15 instead of $5 \mathrm{~min}$ ). Nucleotide analogs that appeared to be incorporated as well as the natural nucleotides, but could in fact be up to threefold less efficiently incorporated, were then retested at lower concentration and shorter time points.

\section{Incorporation of CTP analogs into tRNA-D and tRNA-DC}

Incorporation of CTP analogs into tRNA-DC was tested using the class I enzyme from $S$. shibatae, and the class II enzymes from gram positive B. stearothermophilus and gram negative E. coli. Eight different CTP analogs (Fig. 2A) were tested under standard assay conditions (Materials and Methods; also see above). Overall, the ability of CTP analogs to serve as substrates for the class I and class II enzymes was surprisingly similar, although the two classes exhibit no obvious sequence homology outside the active site signature (Yue et al. 1996).

The sugar-modified CTP analogs $2^{\prime}$-deoxycytidine and 2 '-deoxy-2'-fluorocytidine were not incorporated into the tRNA-DC substrate either at $200 \mu \mathrm{M}$ (Fig. 2B, lanes 1,3) or $2 \mathrm{mM}$ concentration (data not shown). Inhibition by both $2^{\prime}$-deoxy and 2 '-fluoro modification, but not by $2^{\prime}$-amino modification (Sprinzl et al. 1977), suggests that the $2^{\prime}$ hydroxyl group serves as a hydrogen bond donor but does not exclude the possibility that it also serves as an acceptor (Ortoleva-Donnelly et al. 1998; Ryder and Strobel 1999). The highly electronegative 2 '-fluoro substitution favors the C3'-endo conformation of ribose (Ryder and Strobel 1999), but this seems unlikely to explain inhibition because unsubstituted ribose also favors the $\mathrm{C} 3{ }^{\prime}$-endo conformation. The requirement for a $2^{\prime}$ hydroxyl group on the mononucleotide as well as on the $3^{\prime}$ end of the tRNA substrate (Shi et al. 1998b; Hou 2000) suggests that CCA-adding enzymes must discriminate against deoxynucleotide triphosphates and the $3^{\prime}$ ends of DNA in prokaryotes as well as in eukaryotes where the enzyme exists in the nuclear, cytoplasmic, and mitochondrial compartments (Aebi et al. 1990; Wolfe et al. 1996; Hopper 1998; Lund and Dahlberg 1998; Nagaike et al. 2001). Although 2'-deoxycytidine has been reported to serve as a substrate for the yeast CCAadding enzyme (Sprinzl et al. 1977), it was not incorporated into tRNA substrates by the E. coli, rabbit muscle, or rabbit liver CCA-adding enzymes (Fraser and Rich 1973, 1975); moreover, the apparent Michaelis constant for 2'-deoxycytidine triphosphate $\left(K_{m} 1.7 \mathrm{mM}\right)$ is considerably higher than for the natural CTP substrate $(0.2 \mathrm{mM}$; Sprinzl et al. 1977).

Of the base-modified CTP analogs we tested, three were good substrates for both class I and class II enzymes (zebularine, pseudoisocytidine, and 6-azacytidine; retested in the linear range in Fig. 2C, D), two were substrates for the class II enzymes only (5-fluorocytidine and 5-methylcytidine; retested in the linear range in Fig. 2E), and one could not be incorporated by either class I or II enzymes (6azauridine). Assuming that the sugar-phosphate moeities of all the analogs are similarly positioned on the catalytic nucleotidyltransferase motif, we can draw several conclusions: First, the enzyme is unlikely to inspect $\mathrm{N}-1$ because substitution of a C-linked glycosidic bond for the natural $\mathrm{N}$-linked bond in pseudoisocytidine does not interfere with activity. Second, the enzyme is unlikely to recognize the $4-\mathrm{NH}_{2}$ group, as this is absent in zebularine, which is nearly as good a substrate as pseudoisocytidine, which retains the 4- $\mathrm{NH}_{2}$ group (Fig. 2C). Third, positions 5 and 6 are unlikely to be positive determinants because activity is unaffected by substitution of $\mathrm{N}$ for $\mathrm{C}$ at position 5 (pseudoisocytidine) or position 6 (6-azacytidine). Fourth, C-5 substituents (5-fluorocytidine and 5-methylcytidine) probably interfere sterically with binding as these are inactive with the class I enzyme, modestly active with the B. stearothermophilus class II enzyme, and fully active with the E. coli class II enzyme; moreover, increasing the concentration of these C-5-substituted CTP analogs from 200 to $600 \mu \mathrm{M}$ resulted in complete incorporation under standard assay conditions (data not shown). Fifth, and most importantly, the presence of O-4 prevents incorporation (compare 6-azacytidine with 6-azauridine) but the absence of O-4 does not (zebularine), suggesting that O-4 excludes UTP (Yue et al. 1996) either by functioning as an antideterminant or, more likely, by changing the protonation state of $\mathrm{N}-3$ from an acceptor (as in cytidine) to a donor (as in uridine). Very similar results were obtained when we examined incorporation of the same eight CTP analogs into tRNA lacking CCA (tRNA-D; Fig. 3). The sugar-modified CTP analogs 2 '-deoxycytidine and 2 '-deoxy-2'-fluorocytidine were not incorporated (data not shown); zebularine, pseudoisocytidine, and 6-azacytidine were more efficiently incorporated than CTP by the class I enzyme from S. shibatae and the class II enzymes from $B$. stearothermophilus and E. coli (Fig. 3A, and data not shown; compare upper and lower panels of Fig. 5A below for confirmation that the $S$. shibatae enzyme adds two pseudoisocytidines to tRNAD); and only the class II enzymes from B. stearothermophilus and E. coli could use the C-5 modified analogs 5-fluorocytidine and 5-methylcytidine (Fig. 3B, and data not shown). Thus the eight CTP analogs exhibit similar patterns 
A<smiles>CC1OC(OP(C)(=O)O)C(O)C1O</smiles>

(1) $2^{2}$-deoxycytidine<smiles>Nc1nc(=O)[nH]cc1F</smiles>

(2) 5-fluorocytidine<smiles>CC1OC2CC1C(OP(=O)(O)O)C2O</smiles>

(3) 2-deoxy-2-fluorocytidine<smiles>O=c1nccc[nH]1</smiles>

(4) Zebularine<smiles>Nc1nc(=O)cc[nH]1</smiles>

(5) pseudoisocytidine<smiles></smiles>

(6) 6-azacyticine<smiles>Cc1c[nH]c(=O)nc1N</smiles>

(7) 5-methylcytidine
B

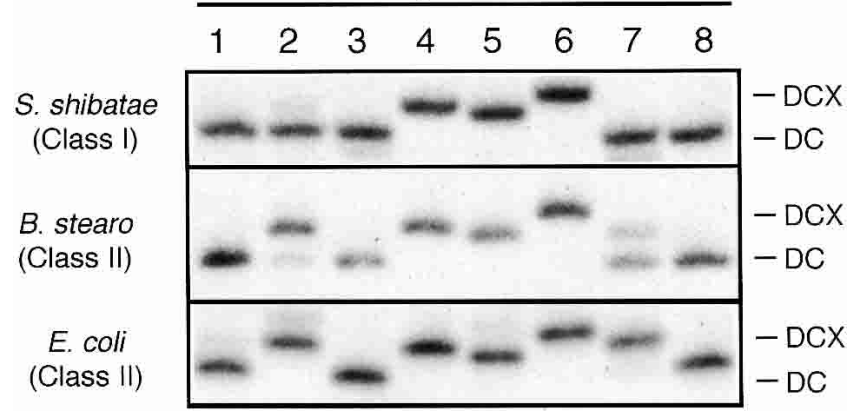

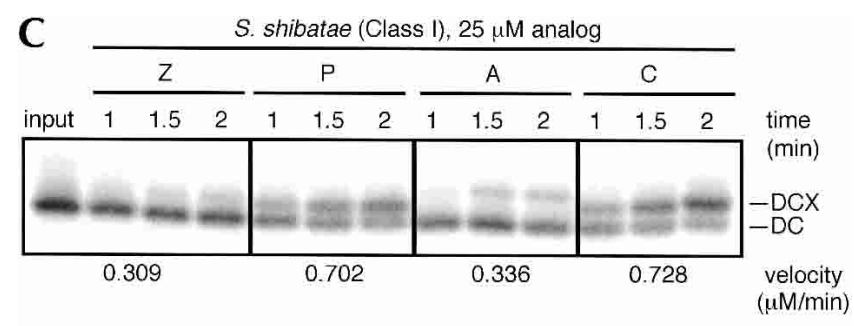
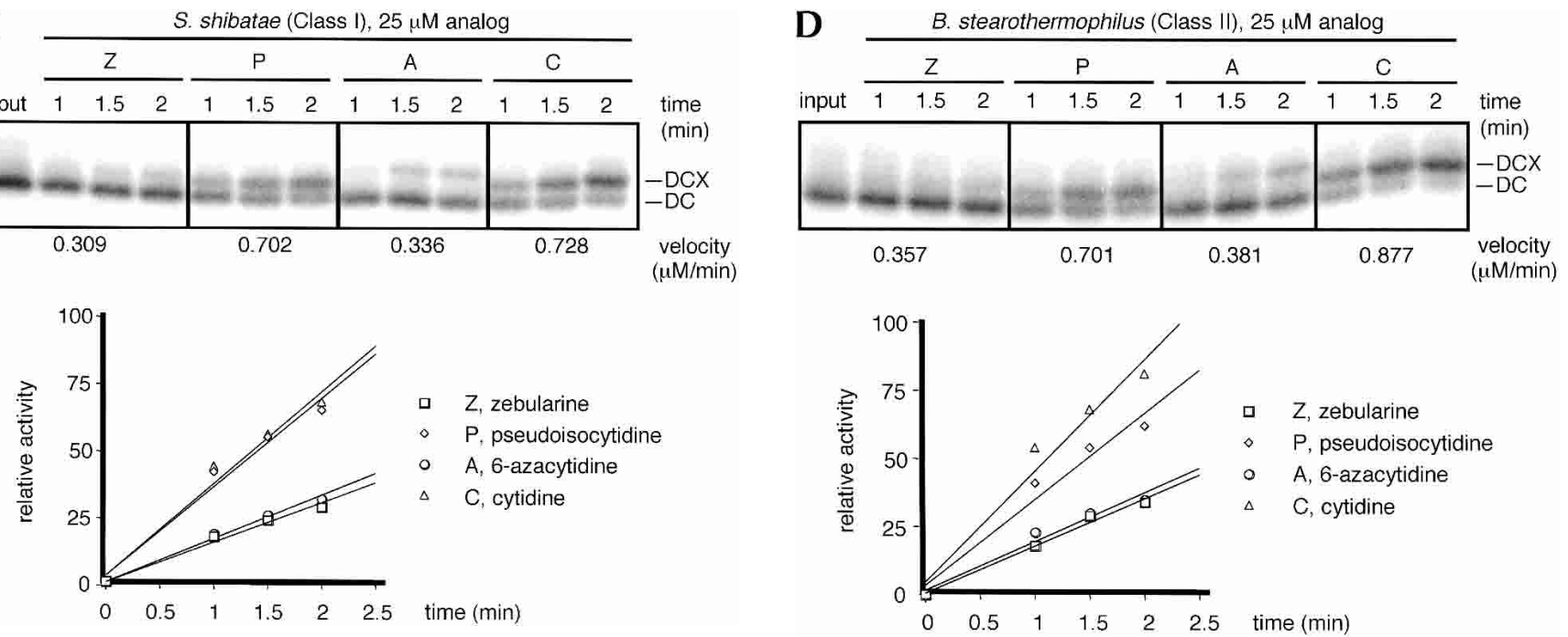

E E. coli (Class II), $200 \mu \mathrm{M}$ analog

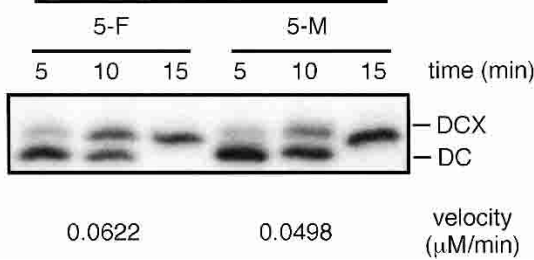

FIGURE 2. Addition of CTP analogs to tRNA-DC. (A) CTP analogs tested, with modifications indicated in red. Analogs are $2^{\prime}$-deoxycytidine (lane 1), 5-fluorocytidine (lane 2), 2'-deoxy-2'-fluorocytidine (lane 3), zebularine (lane 4), pseudoisocytidine (lane 5), 6-azacytidine (lane 6), 5-methylcytidine (lane 7), and 6-azauridine (lane 8). (B) Incorporation of CTP analogs into uniformly labeled tRNA substrates lacking 3'-terminal $\mathrm{CA}$ at high analog concentration $(200 \mu \mathrm{M})$. The CTP reaction goes to completion in 5 min (data not shown); these assays were carried out for 15 min to screen for analogs that are inefficiently incorporated. ( $C$ and $D)$ CTP analogs that were efficiently incorporated in B were retested at lower analog concentration $(25 \mu \mathrm{M})$ for shorter times using the class I enzyme of $S$. shibatae $(C)$ and class II enyzme of B. stearothermophilus $(D)$. (E) CTP analogs that were inefficiently incorporated in B were retested in the linear range; the class I enzyme could not incorporate 5-fluorocytidine or 5-methylcytidine $(B)$. All products were resolved by $12 \%$ denaturing PAGE and visualized by phosphorimaging. Note that in this and subsequent figures, tRNA mobility can depend strongly on the identity of the $3^{\prime}$ terminal nucleotide (for example, cf. lanes $2,4,5,6,7$ in the middle panel).

of incorporation into positions 74 and 75 , suggesting that the enzyme may reuse all or part of a single CTP-binding site. We do not understand why some of the CTP analogs are more efficiently incorporated than CTP; perhaps the enzyme undergoes a conformational change upon binding CTP (see Discussion) but cannot do so with the analogs. 
A

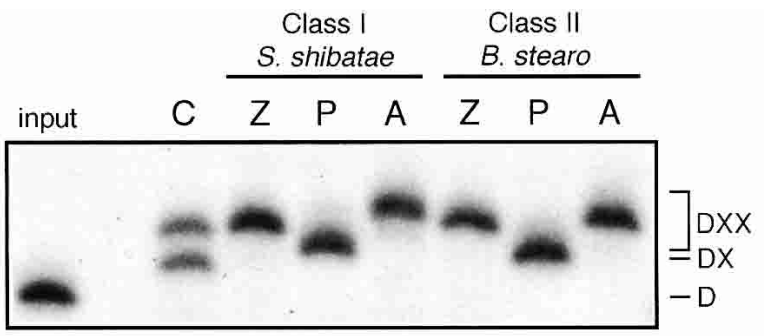

$X=C$, CTP; $Z$, zebularine; $P$, pseudoisocytidine; A, 6-azacytidine

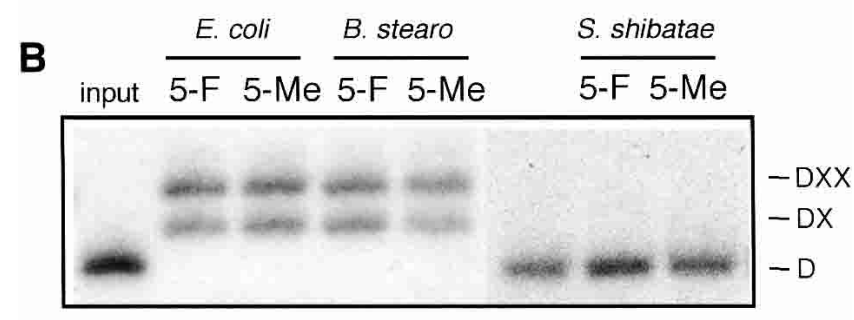

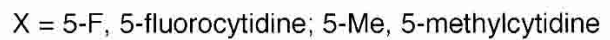

FIGURE 3. Addition of CTP analogs to tRNA-D. (A) Incorporation of CTP analogs zebularine, pseudoisocytidine, and 6-azacytidine into tRNA substrates lacking 3 '-terminal CCA. The CTP control was carried out for only 3 min using low CTP $(25 \mu \mathrm{M})$ to show the mobility of tRNA-DC as well as tRNA-DCC. (B) Incorporation of CTP analogs 5-fluorocytidine and 5-methycytidine into tRNA substrates lacking $3^{\prime}$-terminal CCA. Assays as in Figure 2B.

\section{Incorporation of ATP analogs into tRNA-DCC}

As observed for CTP analogs, the ability of ATP analogs (Fig. 4A) to serve as substrates for class I and class II CCAadding enzymes was surprisingly similar (Fig. 4B).

None of the sugar-modified ATP analogs (2'-deoxyadenosine, $2^{\prime}$-O-methyladenosine, and $2^{\prime}$-deoxy-2'-fluoro-

A

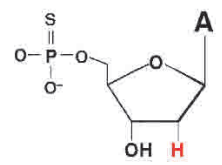<smiles></smiles>
(2) $N^{6}$-methyladenosine<smiles></smiles>

(3) diaminopurine riboside

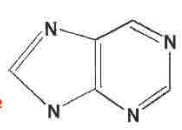

(4) purine riboside
(1) 2'-deoxyadenasine adenosine) were incorporated into tRNA-DCC (Fig. 4B, lanes 1,7,8). As for the CTP analogs (see Fig. 2), this suggests that the 2 '-hydroxyl group is important for recognition, and probably functions as a hydrogen bond donor. Although some 2' substitutions such as 2'-O-methyl could in principle affect the position of the $3^{\prime}$ hydroxyl group, or cause steric hindrance, this seems unlikely, as certain sugarmodified ATP analogs (2'-deoxyadenosine and 2' $-O$-methyladenosine)—as well as CTP analogs (Fraser and Rich 1973, 1975; Sprinzl et al. 1977; also see Fig. 2)—can be incorporated into tRNA substrates by the Saccharomyces cerevisiae and the E. coli class II enzymes when both enzyme and nucleotide analog are present at sufficiently high concentrations to overcome the unfavorable apparent $K_{m}(1.8$ $\mathrm{mM}$ for $2^{\prime}$-deoxyadenosine compared to $0.6 \mathrm{mM}$ for ATP; Fraser and Rich 1973, 1975; Sprinzl et al. 1977).

Although $300 \mu \mathrm{M}$ ATP were efficiently incorporated under standard assay conditions into tRNA substrates lacking A (tRNA-DCC; Fig. 4B, rightmost lane), incorporation of five of the ATP analogs $\left(\mathrm{N}^{6}\right.$-methyl-adenosine, diaminopurine riboside, purine ribose, 2-aminopurine riboside, and 7-deaza-adenosine) was only readily observable at higher concentrations $(1200 \mu \mathrm{M}$ nucleotide for S. shibatae, $600 \mu \mathrm{M}$ nucleotide for B. stearothermophilus and E. coli; Fig. 4B). These results suggest that CTP base modifications are better tolerated than ATP base modifications; that all ATP analogs affect binding affinity or catalysis; and that ATP, and perhaps CTP, are more stringently selected by the class I $S$. shibatae enzyme than by either of the class II enzymes tested.

The ATP analog 7-deaza-adenosine is poorly incorporated by the $S$. shibatae class I and E. coli class II enzymes, even at high concentration, suggesting that the N-7 imine may act as a hydrogen bond acceptor. The $2-\mathrm{NH}_{2}$ group is

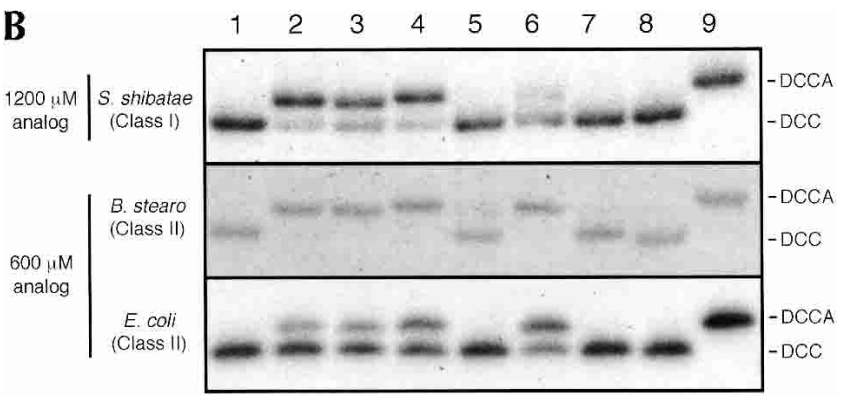

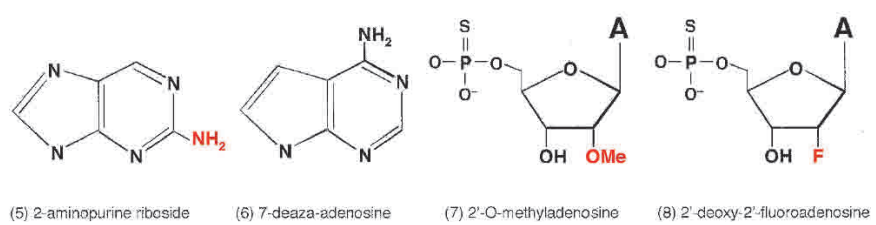

FIGURE 4. Addition of ATP analogs to tRNA-DCC. (A) ATP analogs tested, with modifications indicated in red. (B) Incorporation of ATP analogs into tRNA substrates lacking $3^{\prime}$-terminal A was assayed for the class I S. shibatae enzyme at high analog concentration $(1200 \mu \mathrm{M})$ and $70^{\circ} \mathrm{C}$ (upper panel). The class II B. stearothermophilus and E. coli enzymes were assayed at lower analog concentration $(600 \mu \mathrm{M})$ and $55^{\circ} \mathrm{C}$ or $37^{\circ} \mathrm{C}$, respectively (lower panel). The analogs are 2'-deoxyadenosine (lane 1), N6-methyladenosine (lane 2), diaminopurine riboside (lane 3), purine riboside (lane 4), 2-aminopurine riboside (lane 5), 7-deaza-adenosine (lane 6), 2' -O-methyladenosine (lane 7), 2' -deoxy-2'-fluoroadenosine (lane 8). ATP (rightmost lane) was $300 \mu \mathrm{M}$ in all assays. Under these conditions, the ATP reactions go to completion in 5 min (data not shown); these assays were carried out for $15 \mathrm{~min}$ to screen for analogs that are inefficiently incorporated. Assays as in Figure $2 \mathrm{~B}$. 
an antideterminant for ATP recognition (Fig. 4, cf. purine riboside and 2-aminopurine riboside) but the $6-\mathrm{NH}_{2}$ group is unlikely to be a positive determinant (Fig. 4, cf. $\mathrm{N}^{6}$ methyladenosine and purine riboside), so we suspect that the true positive determinant is unprotonated N-1. To explain use of diaminopurine (Fig. 4), the positive contribution of unprotonated $\mathrm{N}-1$ would overcome the negative contribution of the 2-amino group. Guanosine and inosine would then be unable to serve as substrates (Deutscher 1972; Sprinzl et al. 1977; Sprinzl and Cramer 1979) because the 6-keto group assures protonation of $\mathrm{N}-1$; alternatively, the 6-keto group could be a negative determinant. We also tested the ATP analogs 8-azido-ATP and 2-azido-ATP, but neither the 2- nor 8-azido group interfered with recognition by the CCA-adding enzymes (data not shown). The ability of the enzymes to tolerate the large 2-azido group but not the much smaller 2- $\mathrm{NH}_{2}$ group suggests that inhibition reflects a misplaced hydrogen bond donor/acceptor and not simple steric hindrance. Thus GTP appears to be excluded by the presence of the $2-\mathrm{NH}_{2}$ and 6-keto groups, and by protonation of $\mathrm{N}-1$.

\section{Unnatural 3'-terminal nucleotides can affect the efficiency and specificity of nucleotide addition}

The collaborative templating model for CCA addition, in which the nucleotide-binding pocket is created collaboratively by the enzyme and the growing $3^{\prime}$ end of the tRNA (Shi et al. 1998a), predicts that unnatural $3^{\prime}$ terminal nucleotides may affect the specificity of subsequent nucleotide addition; however, such a specificity switch could also be explained, albeit with greater difficulty, if each nucleotide is bound in a separate site as originally suggested (Deutscher 1982). We therefore examined CCA addition by class I and class II enzymes using CTP analogs as substrates with and without ATP.

Class I and class II enzymes can readily incorporate certain CTP analogs (zebularine, pseudoisocytidine, and 6-azacytidine) into positions 74 and 75 of tRNA lacking $3^{\prime}$-terminal CCA (tRNA-D; Fig. 3A,B). However, neither the class I (Fig. 5A) nor class II enzymes (data not shown) were able to incorporate ATP into a tRNA substrate with one of these analogs at position 75 (tRNA-DCX where $\mathrm{X}$ is zebularine, pseudoisocytidine, or 6-azacytidine). We conclude that these unnatural $3^{\prime}$-terminal $\mathrm{C}$ analogs block ATP addition at position 76 (Fig. 5A) but not CTP addition at position 75 (Fig. 3A).

Substitution of a bulky fluoro or methyl group on the C-5 position of cytidine completely blocks incorporation into position 74 (Fig. 3B) and 75 (Fig. 2B) by the class I S. shibatae enzyme, but it does not prevent incorporation into position 74 and 75 by the class II B. stearothermophilus and E. coli enzymes (Fig. 3B). Moreover, unlike the $3^{\prime}$-terminal $\mathrm{C}$ analogs zebularine, pseudoisocytidine, and 6-azacytidine
(Fig. 5A), neither a single $3^{\prime}$-terminal 5-fluorocytidine at position 75 (tRNA-DCF where $\mathrm{F}$ is 5 -fluorocytidine) nor two consecutive 5-fluorocytidine residues (tRNA-DFF) block ATP incorporation into position 76 (Fig. 5B, upper and lower panels).

\section{Unnatural 3 '-terminal nucleotides may affect the specificity of nucleotide addition}

Curiously, the band we initially thought to be tRNA-DFF (where $\mathrm{F}$ is 5-fluorocytidine) appeared to move slightly slower with ATP than without (Fig. 5B, upper panel, $B$. stearothermophilus). One explanation might have been that tRNA-DFF is converted to tRNA-DFFA in the presence of ATP, followed by $3^{\prime}$-terminal editing to generate tRNADFF $>$ p (where $>$ p indicates a $2^{\prime}, 3^{\prime}$ cyclic phosphate); alternatively, tRNA-DF might have been converted, in the presence of ATP, to tRNA-DFA instead of tRNA-DFF. To distinguish between these and other possibilities, we examined the time course of the reaction, and observed that the slower moving band appears very early, suggesting that it is not tRNA-DFF $>$ p derived from editing of tRNA-DFFA, but is either tRNA-DFF or tRNA-DFA. We next assayed transfer of label from $\left[\alpha^{-}{ }^{32} \mathrm{P}\right]$ ATP to unlabeled tRNA lacking CCA (tRNA-D) in the presence of 5-fluorocytidine or CTP. Interestingly, 5-fluorocytidine generated two bands (presumably tRNA-DFA and tRNA-DFFA) whereas CTP generated a single band (tRNA-DCCA). Moreover, high ATP concentrations increased the putative tRNA-DFA at the expense of tRNA-DFFA (Fig. 5C, cf. lower and upper bands), further suggesting that the middle band in Figure $5 \mathrm{~B}$ is actually tRNA-DFA rather than an editing product with a $2^{\prime}, 3^{\prime}$ cyclic phosphate. Thus substitutions at the $3^{\prime}$ terminus of the tRNA substrate (tRNA-DF) may cause mispacking of the nucleotide-binding pocket, with the result that ATP can be added at position 75 instead of 5-fluorocytidine. In contrast, the natural $3^{\prime}$ terminus (tRNA-DC) never incorporates ATP at position 75. As discussed below, these observations could have implications for the mechanism of nucleotide selection.

The collaborative templating model (Shi et al. 1998a) suggests that modification of the $3^{\prime}$ terminal nucleotide, or of the incoming nucleotide, could cause mispacking of the nucleotide-binding pocket and consequent loss of nucleotide specificity. We therefore asked whether tRNA-DCX (where X represents the CTP analogs zebularine, pseudoisocytidine, and 6-azacytidine) could be extended with GTP or UTP (Fig. 6A) or with a variety of ATP analogs (Fig. 6B). However, neither the class I S. shibatae nor the class II E. coli enzyme was able to add GTP, UTP (Fig. 6A), or any of a large array of ATP analogs (Fig. 6B and data not shown) to these substrates. Indeed, neither class I nor class II enzymes could incorporate any of the ATP analogs into the natural tRNA-D or tRNA-DC substrates (Fig. 6C). 


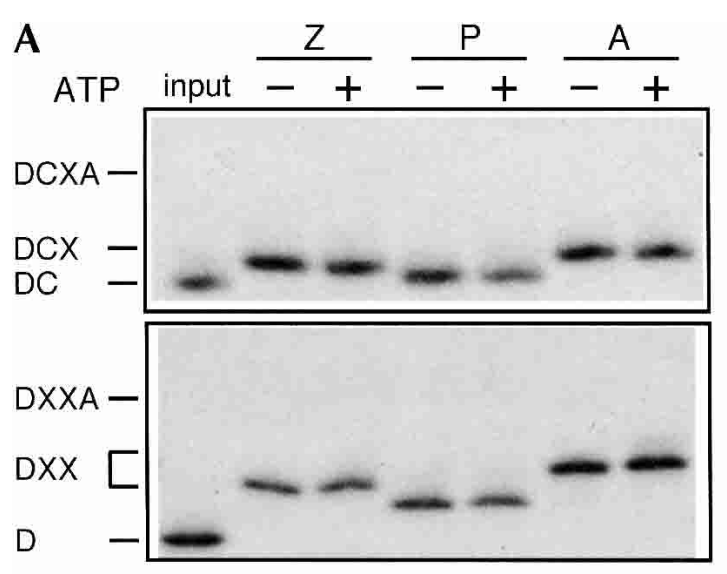

$X=Z$, zebularine; P, pseudoisocytidine; A, 6-azacytidine
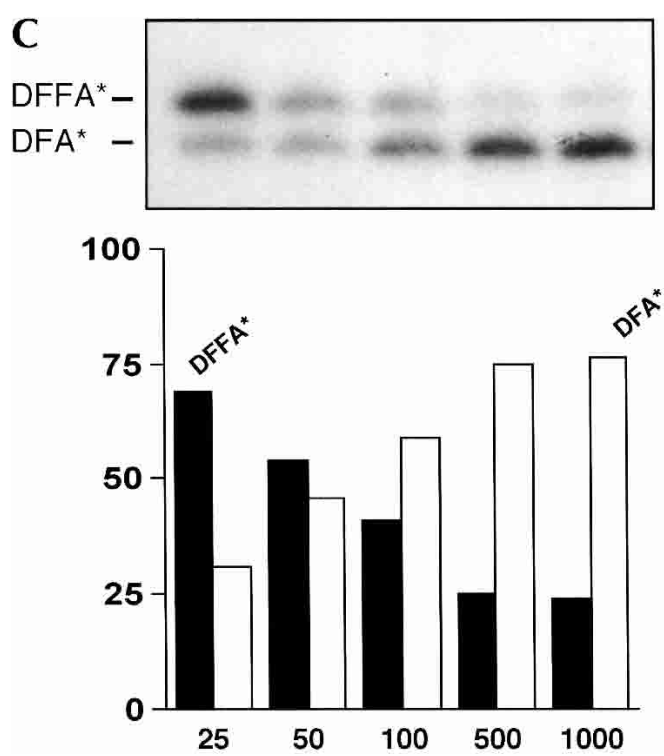
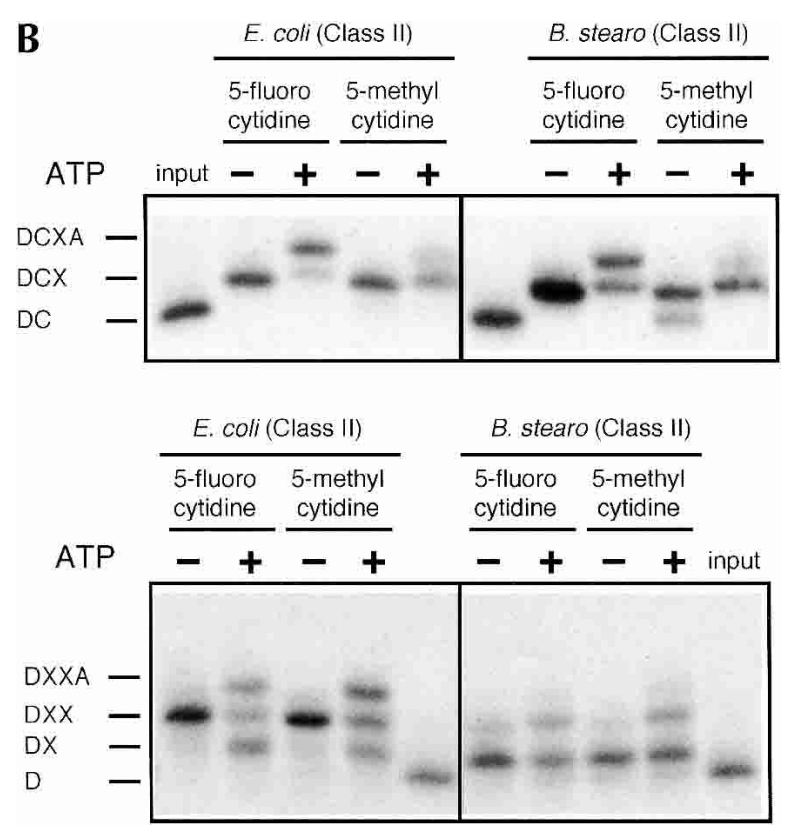

FIGURE 5. The 3'-terminal C analogs block addition of ATP, but not CTP analogs. (A) Addition of CTP analogs zebularine, pseudoisocytidine, and 6-azacytidine $(200 \mu \mathrm{M})$ with or without ATP $(1 \mathrm{mM})$ to tRNA substrates lacking CA (upper panel) or CCA (lower panel). The class I $S$. shibatae was used in this assay. (B) Addition of CTP analogs 5-fluorocytidine and 5-methylcytidine $(500 \mu \mathrm{M})$ with or without ATP (1 mM) to tRNA substrates lacking CA (upper panel) or CCA (lower panel). The class II B. stearothermophilus and E. coli enzymes were assayed at $55^{\circ} \mathrm{C}$ or $37^{\circ} \mathrm{C}$, respectively. $(C)$ Addition of the CTP analog 5 -fluorocytidine $(200 \mu \mathrm{M})$ in the presence of different concentrations of $\left[\alpha-{ }^{32} \mathrm{P}\right] \mathrm{ATP}$ to unlabeled tRNA substrates lacking CCA. The class II B. Stearothermophilus enzyme was assayed for 15 min at $55^{\circ} \mathrm{C}$ and products were resolved by $12 \%$ denaturing PAGE. (F) 5-fluorocytidine. Assays as in Figures 2 and 3.

\section{DISCUSSION}

Conventional RNA and DNA polymerases, as well as reverse transcriptases, faithfully copy a nucleic acid template by exploiting a variety of molecular interactions, including hydrogen bonding between the incoming and template bases; stacking of the newly formed base pair $(n)$ on the previous base pair $(n-1)$; and hydrophobic and/or stacking interactions between the nascent base pair and protein side chains positioned where the next base pair upstream $(n+1)$ will be (Sawaya et al. 1994; Eom et al. 1996; Doublie et al. 1998; Steitz 1998). In effect, the polymerase creates a molecular sandwich where only the correct nucleotide can fit within the confines of the growing duplex.
CCA-adding enzymes are specialized RNA polymerases that can build a specific RNA sequence without using a conventional nucleic acid template. Although several hypotheses have been advanced based on very different kinds of experimental evidence (Deutscher 1982; Shi et al. 1998a; Hou 2000; Li et al. 2000; Tomari et al. 2000; Seth et al. 2002), it is still a mystery how protein alone, or a tRNA/ protein complex, can faithfully template CCA addition. To explore the nature of the interactions between the incoming nucleotides and the protein or tRNA/protein template, we asked whether the CCA-adding enzyme could use a panel of CTP and ATP analogs, and whether incorporation of these analogs would affect either the efficiency or specificity of addition of subsequent nucleotides. To assure the generality 


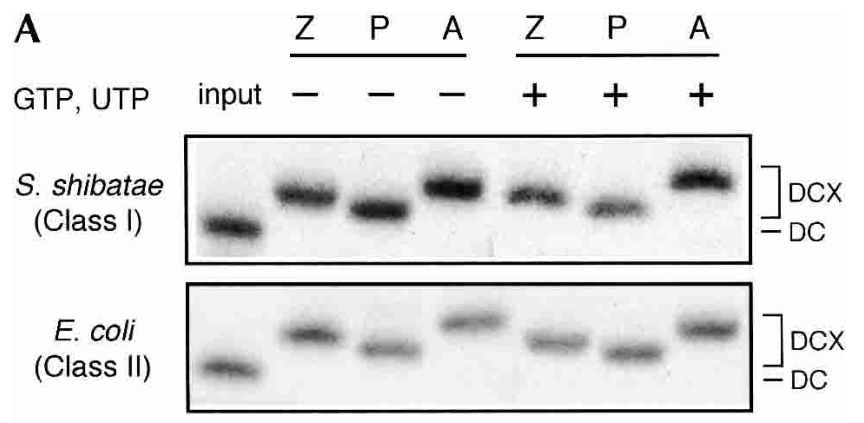

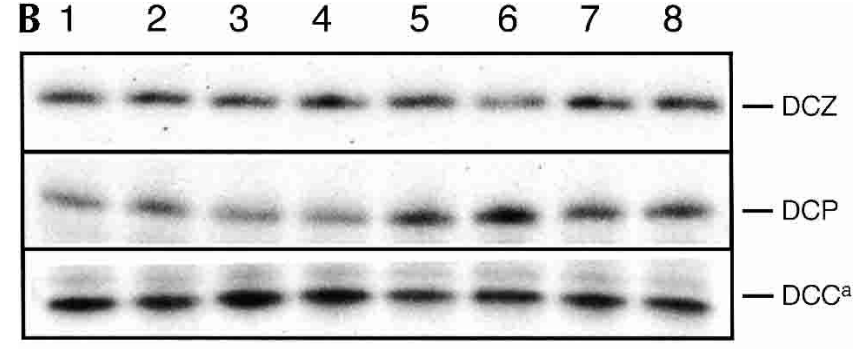

Z, zebularine; P, pseudoisocytidine; $C^{a}, 6$-azacytidine

$X=Z$, zebularine; $P$, pseudoisocytidine; A, 6-azacytidine

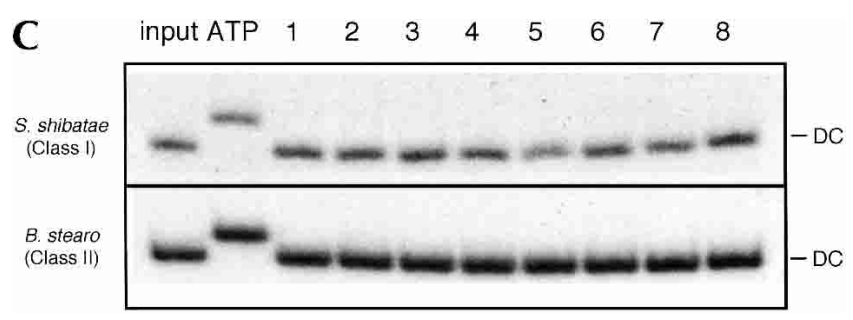

FIGURE 6. The $3^{\prime}$-terminal $\mathrm{C}$ analogs do not relax the specificity of nucleotide addition. (A) Addition of GTP or UTP by class I and class II enzymes tRNA-DCX where X is one of the CTP analogs zebularine, pseudoisocytidine, or 6-azacytidine. Assays as in Figure 5, using CTP analogs $(200 \mu \mathrm{M})$ with or without GTP and UTP (1 mM each). Input tRNA-DC (leftmost lane) is converted to tRNA-DCX (left three lanes) but cannot accept GTP or UTP (right three lanes). (B) Addition of ATP analogs (1 mM) to the tRNA-DCX substrates where X is as in A. ATP analogs (1 $\mathrm{mM}$ ) numbered as in Figure 4A. The class I S. shibatae enzyme was used in this assay. (C) Addition of ATP analogs (1 mM) to tRNA-DC by class I and class II enzymes. Analogs numbered as in Figure 4A (numbered lanes); tRNA-DC substrate only (leftmost lane); positive control containing CTP as well as ATP (second lane from left).

of our results, we tested a class I enzyme from the archaeon S. shibatae $\left(70^{\circ} \mathrm{C}\right.$ growth optimum), and class II enzymes from the gram negative eubacterium E. coli $\left(37^{\circ} \mathrm{C}\right.$ growth optimum) and the gram positive eubacterium B. stearothermophilus $\left(55^{\circ} \mathrm{C}\right.$ growth optimum). The class I and class II enzymes share no obvious sequence similarity outside the immediate vicinity of the nucleotidyltransferase signature (Martin and Keller 1996; Yue et al. 1996; Thurlow et al. 1997; Martin et al. 2000) although this does not rule out structural similarities.

The panel of CTP and ATP analogs (Figs. 2A and 4A, respectively) originally developed for nucleotide analog interference mapping (Strobel and Shetty 1997; Ryder and Strobel 1999) can be regarded as a set of "mutant" nucleotides that probe the role of particular nucleotide substituents and interactions in CCA addition. We discuss the results of this "chemogenetic" approach below in detail, but certain broad conclusions can be drawn as described above in Results. Within the cell, where nucleotide triphosphate analogs do not exist, the only challenge for the CCA-adding enzyme is to distinguish the pyrimidine ribonucleotides (CTP from UTP), the purine ribonucleotides (ATP from GTP), and all four of these from the corresponding deoxyribonucleotides (dNTPs). To meet this challenge, we find that all three CCA-adding enzymes inspect the 2'-hydroxyl of the ribose ring as a key positive determinant. N-3 of cytidine probably serves as a positive determinant to dis- tinguish CTP from UTP, although we cannot exclude the possibility that O-4 serves as an antideterminant (Fig. 2, cf. zebularine, 6-azacytidine, and 6-azauridine). Similarly, N-1 of adenosine probably serves as a positive determinant to distinguish ATP from GTP, and the $2-\mathrm{NH}_{2}$ group as an antideterminant (Fig. 4, cf. diaminopurine riboside, purine riboside, and 2-aminopurine riboside). Surprisingly, the class I and class II enzymes responded similarly to almost all analogs tested, consistent with a conservation of molecular mechanism despite the minimal sequence similarity between class I and class II enzymes outside the nucleotidyltransferase signature (Shi et al. 1998a); however, the class I S. shibatae enzyme was most stringent overall, and the class II E. coli enzyme most permissive (Figs. 2B, 3B, 4B).

The apparent specificity of any enzyme depends on assay conditions. Under our standard assay conditions, with catalytic levels of enzyme (molar ratio of protein to tRNA, 1:100), and physiological levels of tRNA precursors $(2 \mu \mathrm{M})$ and nucleotides $(200 \mu \mathrm{M})$, the class I and class II CCAadding enzymes faithfully add CCA. Neither the class I (Yue et al. 1996) nor class II enzymes (data not shown) incorporate UTP or GTP into tRNA substrates lacking CA or $\mathrm{CCA}$, and we do not observe poly $(\mathrm{C})$ polymerase activity as reported by others when enzyme levels are elevated, the assay is prolonged, or ATP is omitted (Hou 2000; Seth et al. 2002). Although the yeast and liver CCA-adding enzymes were reported to incorporate UTP, the yeast enzyme was 
present in excess, CTP was omitted, and the apparent $K_{m}$ for UTP was more than 40-fold higher than for CTP $(8.8$ $\mathrm{mM}$ versus $0.2 \mathrm{mM}$; Sprinzl et al. 1977; Masiakowski and Deutscher 1980). We also see very weak incorporation of UTP by both class I and class II enzymes, but only when CTP is omitted, UTP and enzyme levels are high, or the assay is prolonged (data not shown).

Although the requirement for unprotonated N-3 may be the major determinant discriminating against UTP (Fig. 2) and unprotonated N-1 the major determinant discriminating against GTP (Fig. 4), other substituents influence the efficiency of incorporation. For example, bulky 5-substitution of CTP analogs is tolerated by the class II enzymes from E. coli and B. stearothermophilus, but not by the more stringent S. sulfolobus enzyme (Fig. 3B). None of the ATP analogs was readily incorporated into tRNA at $300 \mu \mathrm{M}$, although some incorporation was seen at $600 \mu \mathrm{M}$ for the class II enzymes and at $1200 \mu \mathrm{M}$ for the class I enzyme (Fig. 4B). Surprisingly, addition of the large photoreactive azide group in 2- and 8-azido-ATP only mildly inhibited incorporation by class I and class II CCA-adding enzymes (data not shown); however, others have reported that 8-azidoATP cannot be incorporated into tRNA, at least by the class II enzyme of budding yeast (Sprinzl et al. 1977).

Use of CTP and ATP analogs by the CCA-adding enzyme has been investigated previously (Sprinzl et al. 1977; Sprinzl and Cramer 1979) with results resembling our own. Neither $1: N^{6}$-ethenoadenosine nor $1-N$-oxoadenosine serve as substrates for the budding yeast CCA-adding enzyme, implicating purine $\mathrm{N}_{1}$ and $\mathrm{N}_{6}$ in recognition (Deutscher 1972; Secrist et al. 1972; Sprinzl et al. 1977; Sprinzl and Cramer 1979). Guanosine, inosine, and 2-aminopurine riboside also fail to serve as substrates, implicating the purine 6-amino group (Uretsky et al. 1968; Ward et al. 1969; Deutscher 1972; Sprinzl et al. 1977; Sprinzl and Cramer 1979). However, 8-aza-9-deaza-inosine (formycin), 7-deaza-adenosine (tubercidin), 7-deaza-7-cyano-adenosine (toyocamycin), and 7-deaza-7-carboxyamido-adenosine (sangivamycin) all serve as substrates for rat liver CCA-adding enzyme, indicating that $\mathrm{N}_{7}$ is not an essential positive determinant for class II enzymes (Uretsky et al. 1968; Ward et al. 1969).

Incorporation of some $3^{\prime}$-terminal CTP analogs (zebularine, pseudoisocytidine, and 6-azacytidine) blocks subsequent ATP addition (Fig. 5A). Thus, CTP analogs that are efficiently incorporated into positions 74 and 75 can nonetheless block addition of ATP at position 76, suggesting that $\mathrm{C}_{74}$ and $\mathrm{C}_{75}$ do not fit into rigid binding sites on the enzyme but rather create a dynamic structure that must undergo a conformational change before addition of the next nucleotide (Shi et al. 1998a; Hou 2000; Tomari et al. 2000; Li et al. 2002; Seth et al. 2002). In contrast, incorporation of two other 3'-terminal CTP analogs (5-fluorocytidine and 5 -methylcytidine) allows normal addition of ATP at position 76 (Fig. 5B). Most intriguingly, these same two CTP analogs also allow premature addition of ATP at position 75 (Fig. 5C) but not UTP or GTP at position 76 (Fig. 6A), suggesting that the enzyme undergoes a conformational change as each nucleotide is added.

Our nucleotide analog incorporation data alone cannot distinguish between models for CCA addition that postulate multiple nucleotide binding sites (Deutscher 1982; Hou 2000; Tomari et al. 2000), a single nucleotide-binding site built of RNA and protein (Shi et al. 1998a) or protein only (Li et al. 2002), or separate binding sites for CTP and ATP on nonequivalent subunits of a homomultimeric enzyme (Li et al. 2000). For example, our observation that all eight CTP analogs exhibit similar patterns of incorporation into positions 74 and 75 suggests, but cannot prove, that the enzyme reuses a single CTP-binding site. Similarly, although the unusual tRNA species generated by addition of 5-fluorocytidine (Fig. 5) could be consistent with the notion that the growing $3^{\prime}$ end of the tRNA forms part of the nucleotide-binding pocket as in the "collaborative templating" model (Shi et al. 1998a), other interpretations are also possible (see below).

Our functional data can, however, be correlated with the recently determined crystal structures of the B. stearothermophilus class II CCA-adding enzyme complexed with CTP or ATP (Li et al. 2002). In fact, although our interpretation of the nucleotide analog incorporation data was formulated-and our manuscript originally submitted-before the $B$. stearothermophilus structures became available, all of our intepretations are consistent with the nucleotide-binding mechanisms proposed on the basis of structural data alone.

Three key conclusions emerged from complexes of the $B$. stearothermophilus CCA-adding enzyme with CTP and ATP (Li et al. 2002): (1) a single nucleotide binding site can, with only subtle changes, recognize both CTP and ATP; (2) this nucleotide-binding site includes the nucleotidyltransferase motif that catalyzes both CTP and ATP addition (Yue et al. 1998); and, by implication, (3) the specificity of single switchable nucleotide-binding site must be controlled by the identity of the bound tRNA substrate-binding of tRNA-D and tRNA-DC would leave the site in the default CTP-binding mode, whereas binding of tRNA-NCC would switch the site to ATP-binding mode.

The single switchable nucleotide-binding site seen in the crystal structures fits well with our functional data for ana$\log$ use. Specifically, the 2' hydroxyl of the incoming nucleotide functions as a hydrogen bond acceptor to discriminate ribose from deoxyribose (Fig. 2B). UTP is excluded because N-3 of cytidine functions as a hydrogen bond acceptor and positive determinant, whereas the 4-keto group of UTP, unlike the 4-amino group of CTP, is a hydrogen bond acceptor and thus an antideterminant (Fig. 2B). Similarly, GTP is excluded because N-1 of ATP is a hydrogen bond acceptor and positive determinant, whereas the 6-keto group of GTP, unlike the 6-amino group of ATP, 
is a hydrogen bond acceptor and antideterminant. Thus our data suggest that both class I and class II CCA-adding enzymes select CTP and ATP, and discriminate against UTP and GTP, by "base pairing" with the 3 and 4 positions of pyrimidines and the equivalent 1 and 6 positions of purines (Fig. 7), consistent with conclusions based on the crystal structure of a class I enzyme (Li et al. 2002).

To explain how the $3^{\prime}$ terminal nucleotides of the tRNA substrate could switch nucleotide-binding specificity of the active site from CTP to ATP, Li et al. (2002) proposed a "scrunching" model in which bulging of 3 '-terminal C74 and C75 (as for tRNA-DCC) but not C74 alone (as for tRNA-DC) would cause a subtle conformational change in the nucleotide-binding site that would leave the base pairing scheme (Fig. 7) essentially unchanged, but make room for the larger purine and/or disfavor the smaller pyrimidine. Scrunching could also explain how the $3^{\prime}$ terminal sequence of the growing tRNA substrate can affect the efficiency or specificity of subsequent nucleotide addition (Fig. 5): If correct scrunching can switch the specificity from CTP to ATP, incorrect scrunching could potentially miscommunicate with the nucleotide binding site.

Finally, we wish to emphasize that the CTP and ATP complexes of the B. stearothermophilus enzyme were obtained by CTP and ATP soaks of apoenzyme crystals, not by

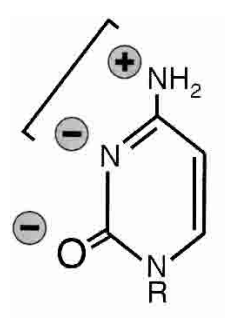

cytidine

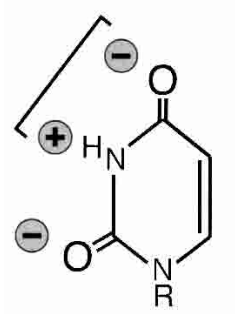

uridine

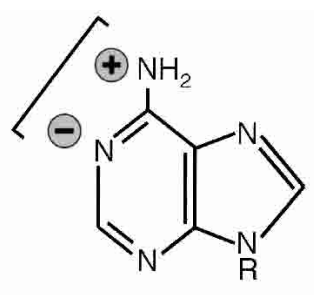

adenosine

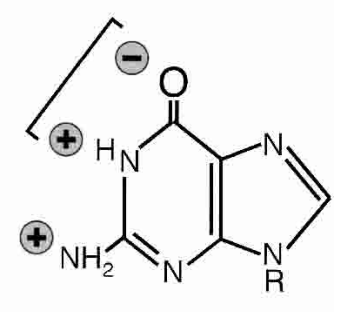

guanosine
FIGURE 7. The enzyme may recognize $\mathrm{C}$ and $\mathrm{A}$, and discriminate against $U$ and $G$, by forming hydrogen bonds ("base pairing") with the 3 and 4 positions of pyrimidines and the equivalent 1 and 6 positions of purines (indicated by brackets, where + indicates hydrogen bond donor and - hydrogen bond acceptor). The cartoon combines functional data (this study) with structural data for the B. stearothermophilus class I CCA-adding enzyme complexed with CTP and ATP (Li et al. 2002). In the crystal structure, the nucleotide-binding site also "base pairs" with N-3 of ATP. cocrystallization; that tRNA substrates were completely absent from all crystal forms; and that only one divalent metal ion was visible in the two-metal ion-binding pocket of the nucleotidyltransferase motif ( $\mathrm{Li}$ et al. 2002). As a result, neither the tRNA binding site nor the disposition of the $3^{\prime}$ end of the tRNA substrate relative to the active site is known. Good agreement between our functional data, based entirely on nucleotide analog studies for class I and class II enzymes, and the proposed nucleotide binding mechanisms, based entirely on structural evidence for a class II enzyme, thus strongly supports the physiological significance of a single switchable nucleotide-binding site that recognizes both CTP and ATP (Li et al. 2002). Our functional data should continue to allow rigorous evaluation of structural hypotheses for nucleotide selection and tRNA binding as additional crystal structures emerge.

\section{MATERIALS AND METHODS}

\section{Recombinant CCA-adding enzymes}

A fragment of the gene for B. stearothermophilus CCA-adding enzyme was amplified from genomic DNA (a kind gift of R. Losick, Harvard University) using degenerate upstream and downstream primers (5'-TAYTTTGTNGGNGGNGCNGTNCGNGA-3' and $5^{\prime}$-NAGCATNCGNAGNGCRAGYTC-3') corresponding to the most highly conserved region of the class II enzymes. The PCR product was cloned into a PCR-TOPO 2.1 vector (Invitrogen) and sequenced to confirm the presence of the nucleotidytransferase active site signature. To identify a restriction fragment containing the entire gene, genomic blots of B. stearothermophilus DNA were probed with the cloned PCR product. A subgenomic library in plasmid pUC19 (NEB) was constructed using size-selected restriction fragments, candidate clones were identified by colony hybridization, and the presence of the complete gene was confirmed by sequencing. To construct an expression clone, the gene was amplified using upstream and downstream PCR primers $\left(5^{\prime}\right.$-TTC GCTCGCCGCAAGGAAGGTGAACATATGAAACCGCC- ${ }^{\prime}$ ' and 5' -TTACGATCCGATAGCCAAGGCGGCGCACCTCGAGAGGT TCAAAGCCTTCTT-3', respectively; NdeI and XhoI sites underlined), and cloned between the NdeI and XhoI sites of the pET-22b expression vector (Novagen) as described (Yue et al. 1996).

Recombinant proteins were expressed in E. coli BL21 (DE3) for $4 \mathrm{~h}$ at $37^{\circ} \mathrm{C}$ following induction with $1 \mathrm{mM}$ IPTG. The bacterial pellet was lysed by sonication in buffer A $(20 \mathrm{mM}$ Tris- $\mathrm{HCl}$ at $\mathrm{pH}$ 7.5, $500 \mathrm{mM} \mathrm{KCl}, 10 \mathrm{mM} \mathrm{MgCl}_{2}, 10 \mathrm{mM} \beta$-mercaptoethanol, 5\% glycerol, and $0.1 \mathrm{mM}$ PMSF), subjected to a clearing spin, and then incubated for $10 \mathrm{~min}$ at $70^{\circ} \mathrm{C}$ to denature most E. coli proteins. After a second clearing spin, soluble recombinant protein was purified by affinity chromatography on nickel-NTA resin (Qiagen), eluted with $150 \mathrm{mM}$ imidazole in buffer A, dialyzed against buffer B (20 mM Tris- $\mathrm{HCl}$ at $\mathrm{pH} 7.5,100 \mathrm{mM} \mathrm{KCl,} 10 \mathrm{mM}$ $\mathrm{MgCl}_{2}, 10 \mathrm{mM} \beta$-mercaptoethanol, $5 \%$ glycerol, and $0.1 \mathrm{mM}$ PMSF), and stored at $-70^{\circ} \mathrm{C}$ in buffer B containing $50 \%$ glycerol. Recombinant E. coli and S. shibatae CCA-adding enzymes were purified essentially as described (Shi et al. 1998b; Yue et al. 1998; Cho et al. 2002). 


\section{tRNA substrates}

All tRNA substrates were prepared by in vitro transcription. The templates for tRNA substrates lacking $3^{\prime}$ terminal A or CA (B. subtilis $\mathrm{tRNA}^{\mathrm{Asp}}$-DCC, or tRNA ${ }^{\mathrm{Asp}}$-DC, where $\mathrm{D}$ is the discriminator base) were FokI-digested or BbsI-digested pmBsDCCA (Oh and Pace 1994). To generate tRNA substrates lacking 3'terminal CCA (B. subtilis tRNA ${ }^{\text {Asp }}$-D), a solitary C was deleted from pmBsDCCA, changing ACCGCCAGGT to ACCGCAGGT and creating a new FokI site for runoff transcription (Tomita and Weiner 2001; Cho et al. 2002). Uniformly labeled tRNAs were transcribed for $30 \mathrm{~min}$ at $37^{\circ} \mathrm{C}$ in a reaction containing $40 \mathrm{mM}$ Tris- $\mathrm{HCl}\left(\mathrm{pH} 8.0,20^{\circ} \mathrm{C}\right), 6 \mathrm{mM} \mathrm{MgCl}, 10 \mathrm{mM}$ dithiothreitol, 2 $\mathrm{mM}$ spermidine, $20 \mathrm{U} / \mu \mathrm{L}$ T7 RNA polymerase (Roche), $500 \mu \mathrm{g} /$ mL DNA template, $500 \mu \mathrm{M}$ ATP, CTP, and GTP, $50 \mu \mathrm{M} \mathrm{UTP}$, and $50 \mu \mathrm{Ci}\left[\alpha-{ }^{32} \mathrm{P}\right] \mathrm{UTP}$ (3,000 Ci/mmole; Amersham Pharmacia Biotech). All tRNA transcripts were purified by denaturing $8 \mathrm{M}$ urea/ $12 \%$ polyacrylamide gel electrophresis to remove minute amounts of incorrectly terminated transcripts, and the single tRNA band was visualized by autoradiography, eluted, and concentrated by ethanol precipitation with glycogen carrier (Roche).

\section{Enzyme assays}

Assays for CTP and ATP incorporation were performed at catalytic enzyme levels (1:100 enzyme to substrate) in reactions containing $500 \mathrm{ng}$ uniformly labeled tRNA substrate with $3^{\prime}$ ends lacking A, $\mathrm{CA}$, or CCA and $20 \mathrm{ng}$ of purified recombinant CCA-adding enzyme in $10 \mu \mathrm{L}$ of $100 \mathrm{mM}$ glycine/ $\mathrm{NaOH}$ (pH 9.0), $10 \mathrm{mM} \mathrm{MgCl}_{2}$, $1 \mathrm{mM}$ dithiothreitol, and varying concentrations of CTP or ATP analogs. The reactions were incubated for $15 \mathrm{~min}$ at $37^{\circ} \mathrm{C}$ (E. coli), $55^{\circ} \mathrm{C}$ (B. stearothermophilus), or $70^{\circ} \mathrm{C}$ (S. shibatae), terminated by addition of $5 \mu \mathrm{L}$ loading buffer [ $95 \%$ formamide, $20 \mathrm{mM}$ sodium EDTA at pH 8.0, xylene cyanol $(0.2 \%)$, and bromophenol blue $(0.2 \%)]$. tRNA products were resolved by denaturing $12 \%$ polyacrylamide gel electrophoresis on a preparative scale $(20 \mathrm{~cm} \times 48$ $\mathrm{cm})$ at $800 \mathrm{~V}$ for $16 \mathrm{~h}$, and autoradiographed or quantitated by phosphorimager analysis (Molecular Dynamics).

\section{Nucleotide synthesis and purification}

Synthesis and purification of all CTP and ATP analogs used here have been described previously (Strobel and Shetty 1997; Ryder and Strobel 1999).

\section{ACKNOWLEDGMENTS}

We thank Erica Jacobs and Kozo Tomita for helpful discussion, Anne Kosek for purification of the nucleotide analog diastereomers, and the referees for invaluable suggestions. A.K.O. was supported by a Jane Coffin Childs Postdoctoral Fellowship. This work was supported by awards from NIH (A.M.W.) and NSF (S.S).

The publication costs of this article were defrayed in part by payment of page charges. This article must therefore be hereby marked "advertisement" in accordance with 18 USC section 1734 solely to indicate this fact.

Received August 8, 2002; accepted April 29, 2003.

\section{REFERENCES}

Abramovitz, D.L., Friedman, R.A., and Pyle, A.M. 1996. Catalytic role of 2'-hydroxyl groups within a group II intron active site. Science 271: 1410-1413.

Aebi, M., Kirchner, G., Chen, J.Y., Vijayraghavan, U., Jacobson, A., Martin, N.C., and Abelson, J. 1990. Isolation of a temperaturesensitive mutant with an altered tRNA nucleotidyltransferase and cloning of the gene encoding tRNA nucleotidyltransferase in the yeast Saccharomyces cerevisiae. J. Biol. Chem. 265: 16216-16220.

Armstrong, V.W., Dattagupta, J.K., Eckstein, F., and Saenger, W. 1976. The base catalysed anomerisation of $\beta$-5-formyluridine; crystal and molecular structure of $\alpha$-5-formyluridine. Nucleic Acids Res. 3: $1791-1780$.

Cho, H.D., Tomita, K., Suzuki, T., and Weiner, A.M. 2002. U2 small nuclear RNA is a substrate for the CCA-adding enzyme (tRNA nucleotidyltransferase). J. Biol. Chem. 277: 3447-3455.

Cramer, F., Faulhammer, H., von der Haar, F., Sprinzl, M., and Sternbach, H. 1975. Aminoacyl-tRNA synthetases from baker's yeast: Reacting site of enzymatic aminoacylation is not uniform for all tRNAs. FEBS Lett. 56: 212-214.

Deutscher, M.P. 1972. Reactions at the $3^{\prime}$ terminus of transfer ribonucleic aid. IV. Extents of normal and anomalous nucleotide incorporation catalyzed by transfer ribonucleic acid nucleotidyltransferase. J. Biol. Chem. 247: 469-480.

1982. tRNA nucleotidyltransferase. The Enzymes 15: 183-215.

Doublie, S., Tabor, S., Long, A.M., Richardson, C.C., and Ellenberger, T. 1998. Crystal structure of a bacteriophage T7 DNA replication complex at $2.2 \AA$ resolution. Nature 391: 251-258.

Eckstein, F. 1985. Nucleoside phosphorothioates. Annu. Rev. Biochem. 54: 367-402.

Eckstein, F. and Gish, G. 1989. Phosphorothioates in molecular biology. Trends Biochem. Sci. 14: 97-100.

Eckstein, F. and Thomson, J.B. 1995. Phosphate analogs for study of DNA polymerases. Methods Enzymol. 262: 189-202.

Eckstein, F., Romaniuk, P.J., and Connolly, B.A. 1982. Stereochemistry of enzymic phosphoryl and nucleotidyl transfer. Methods Enzymol. 87: 197-212.

Eom, S.H., Wang, J., and Steitz, T.A. 1996. Structure of Taq polymerase with DNA at the polymerase active site. Nature 382: 278-281.

Fraser, T.H. and Rich, A. 1973. Synthesis and aminoacylation of 3'amino- $3^{\prime}$-deoxy transfer RNA and its activity in ribosomal protein synthesis. Proc. Natl. Acad. Sci. 70: 2671-2675.

- 1975. Amino acids are not all initially attached to the same position on transfer RNA molecules. Proc. Natl. Acad. Sci. 72: 3044-3048.

Gaur, R.K. and Krupp, G. 1993. Enzymatic RNA synthesis with deoxynucleoside 5'-O-(1-thiotriphosphates). FEBS Lett. 315: 56-60.

Guo, M.J., Hildbrand, S., Leumann, C.J., McLaughlin, L.W., and Waring, M.J. 1998. Inhibition of DNA polymerase reactions by pyrimidine nucleotide analogues lacking the 2-keto group. Nucleic Acids Res. 26: 1863-1869.

Hardt, W.D., Erdmann, V.A., and Hartmann, R.K. 1996. Rp-deoxyphosphorothioate modification interference experiments identify $2^{\prime}$-OH groups in RNase P RNA that are crucial to tRNA binding. RNA 2: 1189-1198.

Hopper, A.K. 1998. Nuclear functions charge ahead. Science 282: 2003-2004.

Hou, Y.M. 2000. Unusual synthesis by the Escherichia coli CCA-adding enzyme. RNA 6: 1031-1043.

Knowles, J.R. 1980. Enzyme-catalyzed phosphoryl transfer reactions. Annu. Rev. Biochem. 49: 877-919.

Li, F., Wang, J., and Steitz, T.A. 2000. Sulfolobus shibatae CCA-adding enzyme forms a tetramer upon binding two tRNA molecules: A scrunching-shuttling model of CCA specificity. J. Mol. Biol. 304: 483-492.

Li, F., Xiong, Y., Wang, J., Cho, H.D., Tomita, K., Weiner, A.M., and Steitz, T.A. 2002. Crystal structures of the Bacillus stearothermophilus CCA-adding enzyme and its complexes with ATP or CTP. Cell 
111: 815-824.

Li, Z. and Deutscher, M.P. 1994. The role of individual exoribonucleases in processing at the $3^{\prime}$ end of Escherichia coli tRNA precursors. J. Biol. Chem. 269: 6064-6071.

Li, Z., Pandit, S., and Deutscher, M.P. 1998. 3' exoribonucleolytic trimming is a common feature of the maturation of small, stable RNAs in Escherichia coli. Proc. Natl. Acad. Sci. 95: 2856-2861.

Lund, E. and Dahlberg, J.E. 1998. Proofreading and aminoacylation of tRNAs before export from the nucleus. Science 282: 2082-2085.

Martin, G. and Keller, W. 1996. Mutational analysis of mammalian poly(A) polymerase identifies a region for primer binding and catalytic domain, homologous to the family $\mathrm{X}$ polymerases, and to other nucleotidyltransferases. EMBO J. 15: 2593-2603.

Martin, G., Jeno, P., and Keller, W. 1999. Mapping of ATP binding regions in poly(A) polymerases by photoaffinity labeling and by mutational analysis identifies a domain conserved in many nucleotidyltransferases. Protein Sci. 8: 2380-2391.

Martin, G., Keller, W., and Doublie, S. 2000. Crystal structure of mammalian poly(A) polymerase in complex with an analog of ATP. EMBO J. 19: 4193-4203.

Masiakowski, P., and Deutscher, M.P. 1980. Dissection of the active site of rabbit liver tRNA nucleotidyltransferase. Specificity and properties of the tRNA and acceptor subsites determined with model acceptor substrates. J. Biol. Chem. 255: 11233-11239.

Nagaike, T., Suzuki, T., Tomari, Y., Takemoto-Hori, C., Negayama, F., Watanabe, K., and Ueda, T. 2001. Identification and characterization of mammalian mitochondrial tRNA nucleotidyltransferases. $J$. Biol. Chem. 276: 40041-40049.

Oh, B.K. and Pace, N.R. 1994. Interaction of the $3^{\prime}$-end of tRNA with ribonuclease P RNA. Nucleic Acids Res. 22: 4087-4094.

Ortoleva-Donnelly, L., Szewczak, A.A., Gutell, R.R., and Strobel, S.A. 1998. The chemical basis of adenosine conservation throughout the Tetrahymena ribozyme. RNA 4: 498-519.

Romaniuk, P.J. and Eckstein, F. 1982. A study of the mechanism of T4 DNA polymerase with diastereomeric phosphorothioate analogues of deoxyadenosine triphosphate. J. Biol. Chem. 257: 7684-7688.

Ryder, S.P. and Strobel, S.A. 1999. Nucleotide analog interference mapping. Methods 18: 38-50.

Sawaya, M.R., Pelletier, H., Kumar, A., Wilson, S.H., and Kraut, J. 1994. Crystal structure of rat DNA polymerase $\beta$ : Evidence for a common polymerase mechanism. Science 264: 1930-1935.

Secrist, J.A., 3rd, Barrio, J.R., and Leonard, N.J. 1972. A fluorescent modification of adenosine triphosphate with activity in enzyme systems: 1,N 6-ethenoadenosine triphosphate. Science 175: 646-647.

Seth, M., Thurlow, D.L., and Hou, Y.M. 2002. Poly(C) synthesis by class I and class II CCA-adding enzymes. Biochemistry 41: 45214532.

Shi, P.Y., Maizels, N., and Weiner, A.M. 1998a. CCA addition by tRNA nucleotidyltransferase: Polymerization without translocation? EMBO J. 17: 3197-3206.

Shi, P.Y., Weiner, A.M., and Maizels, N. 1998b. A top-half tDNA minihelix is a good substrate for the eubacterial CCA-adding enzyme. RNA 4: 276-284.

Sprinzl, M., and Cramer, F. 1979. The -C-C-A end of tRNA and its role in protein biosynthesis. Prog. Nucleic Acid Res. Mol. Biol.
22: 1-69.

Sprinzl, M., von der Haar, F., Schlimme, E., Sternbach, H., and Cramer, F. 1972. Incorporation of 5-iodocytidine into yeast tRNA ${ }^{\text {phe }}$ with tRNA nucleotidyl transferase in vitro. Eur. J. Biochem. 25: $262-266$.

Sprinzl, M., Scheit, K.H., and Cramer, F. 1973a. Preparation in vitro of a 2-thiocytidine-containing yeast tRNA Phe-A73-C74-S2C75A76 and its interaction wiith p-hydroxymercuribenzoate. Eur. J. Biochem. 34: 306-310.

Sprinzl, M., Scheit, K.H., Sternbach, H., von der Haar, F., and Cramer, F. 1973b. In vitro in corporation of $2^{\prime}$-deoxyadenosine and $3^{\prime}$ deoxyadenosine into yeast tRNA Phe using t-RNA nucleotidyl transferase, and properties of tRNA Phe $-\mathrm{C}-\mathrm{C}-2^{\prime} \mathrm{dA}$ and tRNA Phe-C-C-3'dA. Biochem. Biophys. Res. Commun. 51: 881-887.

Sprinzl, M., Sternbach, H., von der Haar, F., and Cramer, F. 1977. Enzymatic incorporation of ATP and CTP analogues into the $3^{\prime}$ end of tRNA. Eur. J. Biochem. 81: 579-589.

Steitz, T.A. 1998. A mechanism for all polymerases. Nature 391: 231232.

Strobel, S.A. and Shetty, K. 1997. Defining the chemical groups essential for Tetrahymena group I intron function by nucleotide analog interference mapping. Proc. Natl. Acad. Sci. 94: 29032908.

Thurlow, D.L., Pulido, G.M., and Millar, K.J. 1997. Unidentified open reading frames in the genome of Methanococcus jannaschii are similar in sequence to an archaebacterial gene for tRNA nucleotidyltransferase. J. Mol. Evol. 44: 686-689.

Tomari, Y., Suzuki, T., Watanabe, K., and Ueda, T. 2000. The role of tightly bound ATP in Escherichia coli tRNA nucleotidyltransferase. Genes Cells 5: 689-698.

Tomita, K. and Weiner, A.M. 2001. Collaboration between CC- and A-adding enzymes to build and repair the 3 '-terminal CCA of tRNA in Aquifex aeolicus. Science 294: 1334-1336.

Uretsky, S.C., Acs, G., Reich, E., Mori, M., and Altwerger, L. 1968. Pyrrolopyrimidine nucleotides and protein synthesis. J. Biol. Chem. 243: 306-312.

Ward, D.C., Cerami, A., Reich, E., Acs, G., and Altwerger, L. 1969. Biochemical studies of the nucleoside analogue, formycin. J. Biol. Chem. 244: 3243-3250.

Wolfe, C.L., Hopper, A.K., and Martin, N.C. 1996. Mechanisms leading to and the consequences of altering the normal distribution of ATP(CTP):tRNA nucleotidyltransferase in yeast. J. Biol. Chem. 271: 4679-4686.

Yue, D., Maizels, N., and Weiner, A.M. 1996. CCA-adding enzymes and poly(A) polymerases are all members of the same nucleotidyltransferase superfamily: Characterization of the CCA-adding enzyme from the archaeal hyperthermophile Sulfolobus shibatae. RNA 2: 895-908.

Yue, D., Weiner, A.M., and Maizels, N. 1998. The CCA-adding enzyme has a single active site. J. Biol. Chem. 273: 29693-29700.

Zachau, H.G. and Hertz, H.S. 1974. Lack of incorporation of 1:N6ethenoadenosine triphosphate into yeast tRNAPhe and tRNASer under standard conditions. Eur. J. Biochem. 44: 289-291.

Zhu, L. and Deutscher, M.P. 1987. tRNA nucleotidyltransferase is not essential for Escherichia coli viability. EMBO J. 6: 2473-2477. 

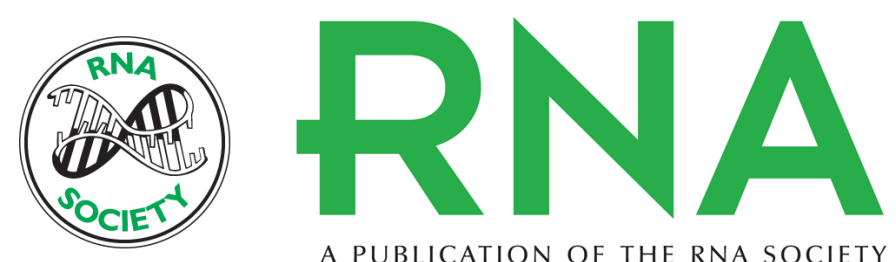

A PUBLICATION OF THE RNA SOCIETY

\section{Use of nucleotide analogs by class I and class II CCA-adding enzymes (tRNA nucleotidyltransferase): Deciphering the basis for nucleotide selection}

HYUNDAE D. CHO, ADEGBOYEGA K. OYELERE, SCOTT A. STROBEL, et al.

RNA 2003 9: 970-981

References This article cites 55 articles, 28 of which can be accessed free at:

http://rnajournal.cshlp.org/content/9/8/970.full.html\#ref-list-1

License

Email Alerting Receive free email alerts when new articles cite this article - sign up in the box at the

Service top right corner of the article or click here. 